\title{
THE EMPLOYMENT OF CONTACT LENSES FOR FLYING DUTIES
}

We have received the following notice from the Air Ministry:

Owing to publicity through columns of the Press which has recently directed attention to contact lenses as an aid to flying in the R.A.F., it is thought that the position should be clarified, so that ophthalmic surgeons prescribing these lenses, dispensing opticians manufacturing them and patients hoping that by wearing contact lenses they can obtain entry into the Service for aircrew duties, may be made aware of the true situation.

Contact lenses are used on certain rare occasions in the Royal Air Force for operational aircrew personnel of experience. The cases are specially selected, depending on their flying skill and experience.

There has never been any idea of accepting personnel into the Service with visual acuity below R.A.F. standards but which can be fully corrected by contact lenses. It is not in the interests of the R.A.F. that this should be so, or that there should be any attempt by enthusiastic applicants to escape detection at medical boards in order to serve their Country in the air. The intention may be highly creditable, but full flying efficiency is not best served in this manner.

\section{ABSTRACTS}

\section{MISCELLANEOUS}

(1) Epidemic|Keratoconjunctivitis. Jl. Amer. Med. Assoc., April 3, 1943.

(1) An acute inflammation of the conjunctiva with involvement of the cornea has made its appearance in epidemic form at several industrial centres in America, especially in ship yards; it has been named epidemic keratoconjunctivitis.

The following description of the disease has been issued by the U.S. Public Health Service and the Committee on Industrial Ophthalmology of the Section on Ophthalmology, American Medical Association.

The incubation period ranges from five to ten days. The onset 
may be preceded by a low fever and mild geperal malaise. The local ocular symptoms are merely those of a foreign body or conjunctival irritation. One eye is usually affected first, and in a large percentage of cases the second eye becomes infected within five to eight days. Preauricular and submaxillary involvement with tenderness is common in a high percentage of eases.

Oedema of the lids and the conjunctiva, especially the transitional fold, is very frequent. The conjunctiva presents the appearance of a simple purulent conjunctivitis; but with little or no formation of pus. Small areas of pseudomembrane are not infrequent and, when removed, leave either small white dotted points or some bleeding points. The bulbar conjunctiva becomes oedematous early. At this stage there is some lacrimation and photophobia, but real pain and blepharospasm do not appear until the cornea becomes involved.

The proportion of cases in which corneal involvement occurs varies between 50 per cent. and 90 per cent. In six to twelve days after the conjunctivitis appears, the cornea becomes involved by the appearance of discrete gray infiltrates that lie in and immediately under the epithelial layer. They may be confined to the periphery of the cornea but in a large percentage of cases involve the pupillary area directly. These infiltrates are discrete and seldom become complicated by an erosion of the corneal epithelium with resultant staining with fluorescein. The extent of visual impairment depends on the number of infiltrates and their location.

The disease is self limited. In the majority of instances the conjunctivitis disappears spóntaneously in fourteen to eighteen days. The corneal complications may disappear in seven days or may last for many months. The longer they persist the greater is the danger of permanent visual impairment.

There is no specific treatment that has shown a definite influence on the course of the disease.

It is not known how long the danger of transmission to others exists. At present for practical purposes a sufferer from epidemic keratoconjunctivitis may be allowed to return to work when the active conjunctivitis has disappeared.

At present the only preventive measure known is complete isolation of infected persons, As the disease has been transmitted through medical personnel the most meticulous asepsis must be insisted on, including eye-droppers and instruments as well as surgeons' hands:

The differential diagnosis has to be considered as follows:-(1) Trachoma with acute onset: here there is neovascularization of the upper fifth of the normally clear cornea or elementary pannus 
(detected on slit-lamp examination) ; vinus inctusion bodies rany detected in 'scrapings of the conjunctival epithelium, suitably stained secundum artem, and much smaller than the vaccinia-like elementary bodies stated to have been found by Gallardo and Hardy (Amer. Jl, of Ophthal., April, 1943, p. 343) in keratoconjunctivitis. (2), Inclusion conjunctivitis: here virus inclusion bodies are invaribly present and are easily found. (3) Beal's conjünctivitis or acute conjunctivitis with follicles: here the cornea is unaffected; follicles are present and there are no inclusion bodies.

\section{A. F. MacCallan.}

(2) Igersheimer, J. (Istanbul).-Anomalies and morbid changes in the small blood vessels of the optic nerve. (Ueber Anomalien und krankhafte Zustände der kleinen Gefässe des Opticus). Ophthalmologica, Vol. CIII, p. 230, April, 1942.

(2) Igersheimer reports two histological studies to show that, contrary to the general opinion, the central artery of the retina gives off no branches in the trunk of the optic nerve; twigs a few millimetres behind the lamina cribosa can be demonstrated. He holds that in such cases the central artery would contribute to the nutrition of the optic nerve. In severe arterio-sclerosis pathological changes in the vessels are found, not only in the retina but also in these small vessels; such changes may lead to atrophy of the optic nerve.

ARNOLD SORSBY.

(3) Verhage, J. W. C. (Hengelo).-Clinical study on latent nystagmus. (Eine klinische Studie ueber den Nystagmus latens). Ophthalmologica, Vol. CIII, p. 209, April, 1942.

(3) Verhage investigated 30 cases of latent nystagmus and found that 27 . of them occurred in patients under the age of 30 . One third of the group showed mental or cerebral changes. The most significant associated eye condition was a hyperphoria alternating with rotary movements of the eye on closure of the lids. $\mathrm{He}$ holds that this is a tendency latently present in normal individuals, becoming active only in conditions in which there is instability of the ocular motor apparatus." The theoretical significance of these findings is discussed.

ARNOLD SORSBY.

(4) Van Heuven, C. J. (Amsterdam).-Leiomyoblastoma iridis). Ophthalmologica, Vol. ÇIII, p. 308, May, 1942.

(4) To the scanty number of leiomyoblastoma of the iris Van Heuven adds another histological report showing the characteristic 
complex structure of muscle and naevoid elements. The tumour occurred in a woman a'ged 54 years.

ARNOLD SORSBY.

(5), Haldimann, C. (Berne)--Late traumatic rosette of the lens. (Beitrag zur traumatischen Spatrosette der Linse: Ophthalmologica, Vol. CIII, p. 302, 1942.

(5) Haldimann reports several cases of traumatic rosette cataract seen in. the early stage and followed up. At the beginning there were two layers of opacity, one being a grey sub-capsular opacity and the other a yellow opacity in the zone of discontinuity with a nucleus. Both these layers of opacity showed leaf figures when sufficiently developed. In the course of a few months the deeper opacity became more marked and the superficial one partly resorbed. Both these layers of opacity tended to spread backward.

\section{ARNOLD SORSBY.}

(6) Bischler, V. (Geneva).-A case of-occupational argyrosis with considerations on metallic impregnation of the cornea. (Considèrations sur les imprégnations métalliques de la cornée à propos d'un cas d'argyrose professionelle). Ophthalmologica, Vol. CIII, p. 281, May, 1942.

(6) Bischler reports the case of a 70 year old man, a silver engraver by occupation, whose left eye showed pigmentation reminiscent of the Kayser-Fleischer ring. There were somewhat similar changes in the right eye, in which, however, the whole of Descemet's membrane was involved. Dark adaptation was diminished and the history excluded any other factor besides exposure to silver salts in the course of the patient's work. An extensive summary of metal impregnation of the cornea is given.

\section{ARNOLD SORSBY.}

(7) Gluck, E. (Budapest).-Clinical experiences with sodium lamp. Ophthalmologica, Vol. CIII, p. 369, June, 1942.

(7) In' a short article Gluck confirms the experiences of other observers with a sodium lamp, and stresses that it has no advantages in retinoscopy, but that it helps to determine the level of corneal changes and that the scars of interstitial keratitis stand out well.

ARNOLD SORSBY.

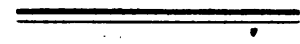

